\title{
Patient assessment of treatment satisfaction: methods and practical issues
}

\section{A Revicki}

Gut 2004;53(Suppl IV):iv40-iv44. doi: 10.1136/gut.2003.034322

\begin{abstract}
Measurement of treatment satisfaction in gastrooesophageal reflux disease (GORD) is compromised by an insufficient conceptual foundation and poor assessment methods. The current state of the art in measuring treatment satisfaction is incomplete, and the existing measurement is insufficient. Here, the definition, conceptualisation, application, and methodological issues associated with measurement of treatment satisfaction in GORD are reviewed. Treatment satisfaction may be important for differentiating among GORD treatments, and for monitoring patient outcomes in clinical practice.
\end{abstract}

\begin{abstract}
SUMMARY
Treatment satisfaction is a patient reported outcome that may give both useful insights into the patient's perspective on their current treatment and differentiation among alternative treatments. Measurement of treatment satisfaction in gastro-oesophageal reflux disease (GORD) is compromised by an insufficient conceptual foundation and poor assessment methods. Treatment satisfaction is defined as the individual's rating of important attributes of the process and outcomes of his/her treatment experience. Previous studies have demonstrated high rates of satisfaction with surgical treatments $(85-92 \%)$ and medical treatments for GORD (70-94\%) but most of these studies used simple global or single item measures. Use of attitude response scales and acquiescent response bias skew individual responses to satisfaction questions, inflate reliability estimates, and may bias treatment comparisons for older, low education, and low income subgroups. The current state of the art in measuring treatment satisfaction is incomplete, and the existing measurement is insufficient. Future instrument development for clinical trials requires more attention to conceptual issues, patient based qualitative research, and evaluation of psychometric qualities. Treatment satisfaction may be important for differentiating among GORD treatments, and for monitoring patient outcomes in clinical practice.
\end{abstract}

\section{INTRODUCTION}

Treatment satisfaction is one of the family of patient reported outcomes (PROs) that is potentially useful for understanding the patient's perspective on their current treatment and that can differentiate among alternative treatments. Treatment satisfaction represents an important outcome as it is related to adherence and willingness to continue treatment. PROs include health related quality of life (HRQoL), self reported symptoms, functional status, and other end points derived from direct reports of patient experience. These PROs are frequently used to evaluate the impact of disease and treatments on the patient's functioning, well being, and everyday life in clinical trials and other studies, including gastrointestinal disease. ${ }^{1}$ Measurement of treatment satisfaction in GORD, and for other gastrointestinal diseases, is compromised by an insufficient conceptual foundation and poorly developed assessment methods.

The primary objectives of this report are to review the definition, conceptualisation, application, and methodological issues associated with measurement of treatment satisfaction in GORD. This is not a comprehensive review of the literature on treatment satisfaction but examples are taken from the published literature to illustrate different issues and applications for clinical trials. Research on the relationship between treatment satisfaction and expectations, and demographic, physician, and health care system variables is summarised. Finally, comment is made on the use of satisfaction with treatment end points in making claims related to treatments for GORD.

\section{DEFINITION AND CONCEPTUAL ISSUES}

Treatment represents the application of different health care interventions for the cure or reduction of disease related symptoms. Treatment satisfaction is defined as the individual's rating of important attributes of the process and outcomes of his/her treatment experience. ${ }^{2}$ Treatment satisfaction focuses on one aspect of satisfaction with medical care ${ }^{3-5}$ and involves the interaction of expectations, preferences, and satisfaction with medical treatment. ${ }^{6}$ Whereas health status instruments measure the outcomes of treatment (for example, biological/physiological, symptoms, functioning, and well being), treatment satisfaction scales assess the level of satisfaction with these health status outcomes.

Weaver and colleagues ${ }^{2}$ have provided a conceptual framework for understanding treatment satisfaction. This conceptual framework, in

Abbreviations: GORD, gastro-oesophageal reflux disease; PROs, patient reported outcomes; HRQoL, health related quality of life; SODA, severity of dyspepsia assessment; TSQ, treatment satisfaction questionnaire 
a somewhat modified form, is depicted in fig 1. Factors within the patient influence reports about satisfaction with treatment. Patient expectations, demographic characteristics, such as age and education, and personal preferences all affect treatment satisfaction. Expectations for treatment are clearly linked with perceptions of satisfaction. ${ }^{6}$ The pattern and characteristics (that is, side effects, effectiveness) of previous treatments for GORD, and the duration of GORD influence perceptions of treatment satisfaction. For example, patients treated with proton pump inhibitors may have high expectations for freedom from symptoms when prescribed new therapies. Clearly, the health care system, in general, influences satisfaction with medical care and treatment satisfaction.

More important are the factors most directly connected to the treatment, and the way the treatment is delivered and directly experienced by the patient (see fig 1). Process factors cover issues associated with access to therapy, treatment related information, and cost (for example, prescription price or insurance co-pays). Outcomes of treatment represent an important determinant of treatment satisfaction, including impact on symptoms and adherence with the treatment regimen. For example, there is a strong relationship between treatment satisfaction and severity of GORD (see fig 2 ) where patients experiencing no or very mild symptoms are more satisfied compared with those with moderate or severe symptoms (Revicki, unpublished data, 2002). The complexity, discomfort, and convenience associated with treatment also affect patient perceptions and evaluations of satisfaction with the treatment. Finally, the individual's intentions, as manifested by their willingness to continue therapy, or his/ her preference for, or choice of, the treatment over other alternative treatments are relevant.

Several domains have been identified within the treatment satisfaction construct based on reviews of the literature ${ }^{2}$ and qualitative research (Coyne and Revicki, unpublished manuscript, 2002). A number of domains have been identified with treatment satisfaction, including treatment related effectiveness, discomfort, cost, regimen characteristics, and preference for continuing therapy (see table 1). In the review by Weaver and colleagues ${ }^{2}$ the domains most often included in treatment satisfaction measures cover overall satisfaction $(47 \%)$, outcomes of treatment $(47 \%)$, disease related information $(37 \%)$, treatment related discomfort $(31 \%)$, product design or appearance $(31 \%)$, and convenience $(31 \%)$.

\section{TREATMENT SATISFACTION INSTRUMENTS}

Treatment satisfaction assessment in GORD, and gastrointestinal disease in general, is mostly limited to one or two

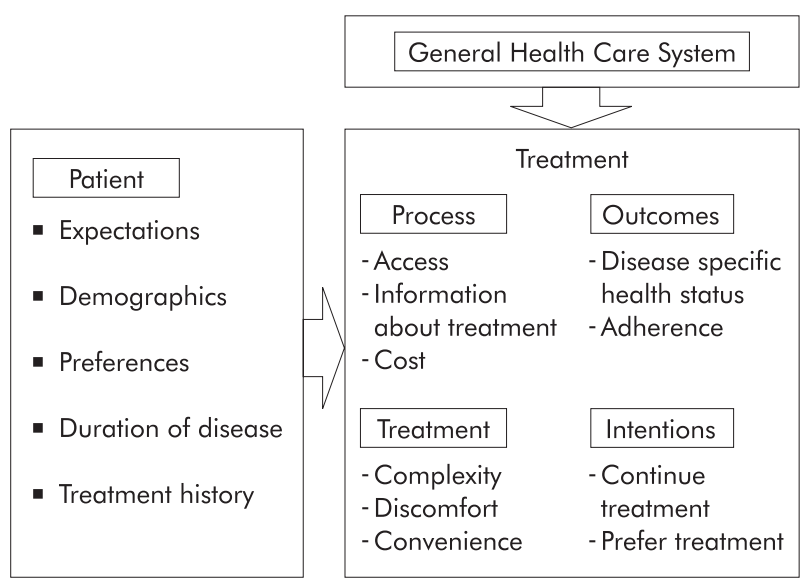

Figure 1 Conceptual framework for treatment satisfaction (source: adapted from Weaver and colleagues ${ }^{2}$ ).

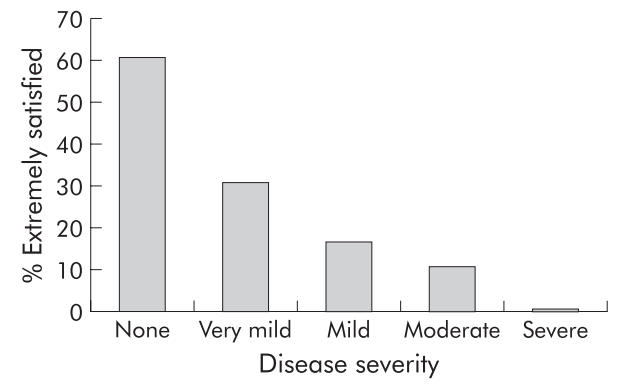

Figure 2 Treatment satisfaction by disease severity: gastrooesophageal reflux disease $(n=689)$ (source: Revicki, unpublished data, 2002).

simple questions on whether the patient is satisfied with the treatment, measured as "yes", "no", or "don't know", or by modified Likert scales ranging from "very satisfied" to "very dissatisfied". The general psychometric literature ${ }^{7}$ and research on measuring satisfaction with medical care $^{389}$ indicates that single item measures may be less reliable and sensitive to treatment differences than multi-item measures.

\section{Treatment satisfaction studies in GORD}

Several previous studies have demonstrated high rates of satisfaction with surgical treatments $(85-93 \%$ satisfied) for GORD. ${ }^{10-15}$ Klingler and colleagues ${ }^{15}$ found that $92 \%$ of patients treated with laparoscopic antireflux surgery for oesophageal strictures refractory to medical therapy were satisfied with their treatment. In this study, satisfaction with therapy was measured using a single item on satisfaction that allowed responses of "yes", "no", or "indifferent". These studies generally used simple global or single item measures, and no data on psychometric characteristics of the treatment satisfaction end points were provided.

Similar relatively high rates of satisfaction with medical treatments for GORD (70-94\% satisfied) have also been observed in studies with cisapride, ${ }^{16}$ omeprazole, ${ }^{17}$ effervescent ranitidine tablets, ${ }^{18-21}$ lansoprazole, ${ }^{22}{ }^{23}$ and rabeprazole. ${ }^{24}$ Bate and colleagues ${ }^{17}$ found that GORD patients treated with omeprazole reported significantly greater levels of treatment satisfaction compared with those treated with cimetidine. Effervescent ranitidine was preferred to standard ranitidine ${ }^{19}$ and famotidine wafers were preferred more than ranitidine tablets ${ }^{18}$ or effervescent ranitidine..$^{20}$ Nelson and colleagues ${ }^{22}$ found that patients treated with omeprazole who were later converted to lansoprazole reported reductions in their satisfaction with their GORD treatment. Crawley and Schmitt, ${ }^{25}$ in a large survey of patients with self reported chronic heartburn, found that $45 \%$ of $\mathrm{H}_{2}$ receptor antagonist treated patients compared with $58 \%$ of proton pump inhibitor treated patients were totally satisfied with their therapy. Mathias and colleagues ${ }^{23}$ found that satisfaction with treatment was better for lansoprazole treated compared with ranitidine treated patients with GORD. The treatment satisfaction scale used in the study by Mathias and colleagues $^{23}$ included four items covering how pleased they

\section{Table 1 Treatment satisfaction domains}

Effectiveness of treatment (that is, symptom relief, speed of onset, duration of effects)

Discomfort with treatment (that is, bother, side effects)

Treatment regimen characteristics (that is, convenience, flexibility)

Preference/desire for continuing treatment

Purchase/cost of treatment

Source: Weaver and colleagues, ${ }^{2}$ Coyne and Revicki, unpublished data, 2002 
were with their medication, how much they benefited from their medication, whether they would recommend their treatment, and how they rated their current medication compared with previous medications. Global assessment of satisfaction with treatment was incorporated into a large open label study of rabeprazole in erosive oesophagitis. ${ }^{24}$ The results suggested that $88 \%$ of patients were satisfied with rabeprazole therapy but this study did not include a control group so it is difficult to interpret these findings.

As in the reflux surgery studies, most of the GORD medication studies used simple global or single item measures. No information is generally provided as to the measurement characteristics (that is, reliability, validity) of these measures. However, in the study by Mathias and colleagues, ${ }^{23}$ a multi-item treatment satisfaction scale was used with some evidence supporting reliability and validity. ${ }^{26}$

\section{Instruments including treatment satisfaction}

Several instruments are available that include treatment satisfaction items or subscales, including the gastrooesophageal reflux data sheet, ${ }^{27}$ GORD-HRQL, ${ }^{26}$ and the severity of dyspepsia assessment (SODA). ${ }^{28}$ There are few data on the reliability and construct validity of these instruments (see table 2). More recently, the treatment satisfaction questionnaire (TSQ) was developed to measure treatment satisfaction in GORD (Coyne and Revicki, unpublished manuscript, 2002) based on a conceptual framework for treatment satisfaction and patient focus groups. The instrument contains seven subscales measuring symptoms, satisfaction, PRN, expectations, cost, and physician and bother domains of treatment satisfaction. The TSQ has good reliability $(r=0.66-0.96)$ and acceptable content validity, construct validity, and responsiveness.

In general, there is an absence of an underlying theoretical or conceptual model for the existing treatment satisfaction measures. Few of these instruments included qualitative data (for example, interviews, focus groups, cognitive interviewing) derived from patients to find out what domains are important to the consumers of GORD therapies as part of the development programme. The only multi-attribute treatment satisfaction instrument is the TSQ, and most of the existing measures consist of single item and global assessments. In addition, there are several measurement problems in many of these measures, including poorly worded items, acquiescent response bias, and response scales that may produce positive bias in patient reports on treatment satisfaction.

There are only limited data on psychometric qualities (that is, reliability, validity) of these measures, except for the GORD-HRQL, SODA, and TSQ. SODA assesses satisfaction with dyspepsia related health and not treatment satisfaction. TSQ has good reliability and is correlated with symptom severity, GORD symptoms, and disease specific and generic health status measures (Coyne and Revicki, unpublished

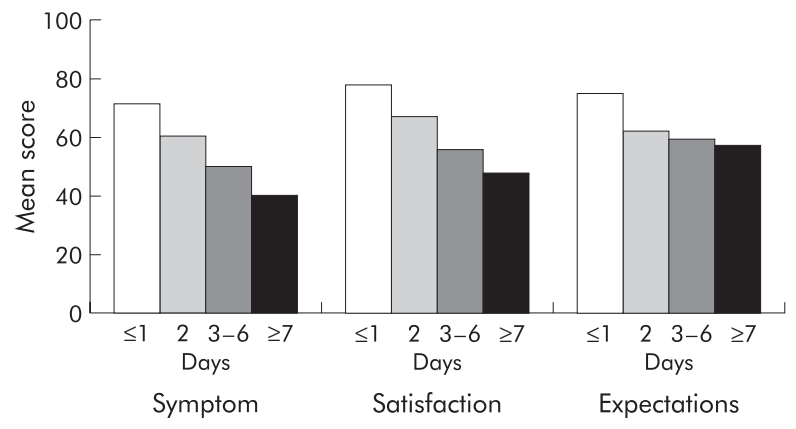

Figure 3 Mean treatment satisfaction questionnaire scores by days with symptoms (source: Coyne and Revicki, unpublished data, 2002).

manuscript, 2002). For example, the satisfaction and symptoms domains in the TSQ were more closed associated with days with GORD symptoms than the expectations domain of the TSQ (see fig 3). Other measures of treatment satisfaction have shown less consistent relationships with symptom severity, frequency, and reduction and effectiveness of treatment.

\section{MEASUREMENT METHODS}

There are several key measurement problems associated with assessment of medical satisfaction and with treatment satisfaction. ${ }^{23892930}$ Most of the methodological research completed to date focuses on measuring satisfaction with medical care. Use of attitude response scales, acquiescent response bias, social desirability, and concern about negative consequences skew individual responses to satisfaction questions, inflate reliability estimates, and may bias treatment comparisons. Substantial acquiescent response bias is found across all methods for assessing patient satisfaction. $^{8931}$ For example, Ross and colleagues ${ }^{9}$ found that favourable responses to satisfaction evaluations ranged from $63 \%$ to $82 \%$ depending on the measurement method. Older respondents, those with less education, and those with poorer health were most highly acquiescent. Evaluative response scales (that is, "poor" to "excellent") were less subject to acquiescent response bias than attitudinal scales (that is, "very satisfied" to "very dissatisfied"; "strongly agree" to "strongly disagree"), and multi-item measures that include balanced positively and negatively worded items were somewhat less subject to acquiescent response bias. ${ }^{8}{ }^{9}$ Social desirability and concern about possible consequences of a negative evaluation affect patient ratings on satisfaction scales. $^{30}$

Although most treatment satisfaction measures included in clinical studies are global single item scales, multi-item scales increase score variability and reliability, and are more

Table 2 Available gastrointestinal disease related instruments with satisfaction measurement

\begin{tabular}{|c|c|c|c|c|c|c|}
\hline \multirow[b]{2}{*}{ Instrument } & \multirow[b]{2}{*}{ Content } & \multirow[b]{2}{*}{ Items } & \multirow[b]{2}{*}{ GI disease } & \multicolumn{3}{|c|}{ Psychometric evidence } \\
\hline & & & & Reliability & Validity & Responsiveness \\
\hline Gastro-oesophageal reflux data sheet ${ }^{27}$ & $\begin{array}{l}\text { GORD related symptoms, } \\
\text { item on satisfaction }\end{array}$ & 10 & GORD & 0 & 0 & + \\
\hline GORD-HR-QoL questionnaire ${ }^{26}$ & $\begin{array}{l}\text { SF-12, symptoms, problems } \\
\text { related to activities, treatment } \\
\text { satisfaction }\end{array}$ & 57 & GORD & + & + & 0 \\
\hline Severity of dyspepsia assessment ${ }^{28}$ & $\begin{array}{l}\text { Dyspepsia related symptoms, } \\
\text { satisfaction with health }\end{array}$ & 17 & Dyspepsia & + & 0 & + \\
\hline $\begin{array}{l}\text { Treatment satisfaction questionnaire } \\
\text { (Coyne and Revicki, unpublished } \\
\text { data, 2002) }\end{array}$ & $\begin{array}{l}\text { Multidomain treatment } \\
\text { satisfaction }\end{array}$ & 41 & GORD & + & + & + \\
\hline
\end{tabular}


sensitive to small to moderate clinical effects. ${ }^{389}$ More attention needs to be focused on documenting the psychometric characteristics of treatment satisfaction instruments, including the conceptual model, reliability, validity (that is, content, construct), responsiveness, and interpretation of meaningful changes in scores. There needs to be a better understanding of the cognitive processes underlying attitude measurements, such as treatment satisfaction, and qualitative research is needed to complete this research. ${ }^{32}$ Attention also needs to focus on variations by language translations and cultural adaptation and differences.

\section{CONFOUNDING VARIABLES AND COVARIATES}

Several demographic characteristics (that is, age, sex, education), health and symptom status, health care system variables (that is, physician-patient relationship, delivery of medical care, other health care attributes), patient expectations, and treatment history are associated with responses to medical and treatment satisfaction instruments. In terms of demographic characteristics, it has been found that patient satisfaction measures vary by age, education level, and income level. ${ }^{93}$ Treatment satisfaction ratings are more positive, in general, in the elderly, but evidence in less conclusive for sex and other demographic variables.

Several studies in other chronic diseases have found evidence for the relationship between effectiveness of therapy and patient ratings of treatment satisfaction. ${ }^{2}$ Marshall and colleagues $^{34}$ found that patient satisfaction was significantly associated with mental health status but not physical health status. A more recent study (Coyne and Revicki, unpublished manuscript, 2002) found significant relationships between reflux symptoms, quality of life in reflux and dyspepsia (QOLRAD) scale total scores, SF-36 physical and mental health scores, and TSQ symptom and satisfaction scores (see table 3 ). In addition, there are a number of clinical studies demonstrating the implied or direct relationship between absence of GORD related symptoms and treatment satisfaction. ${ }^{16-24}$ Kurata and colleagues ${ }^{35}$ found that satisfaction with medical care among dyspepsia patients was associated with improvements in symptom response, while prescribed medication was not associated with satisfaction.

Aspects of the patient-physician interaction and relations impact on measures of satisfaction with medical care ${ }^{36}$ and are likely to be associated with treatment satisfaction. The quality of the interaction, physician expressed effect, communication style, and level of information provision all impact ratings of satisfaction. Patient expectations are closely associated with their ratings of satisfaction with medical care. $^{6}{ }^{37} 38$ In general, when patient's expectations are met within the medical encounter, they report more satisfaction with medical care. Health system characteristics impact on patient satisfaction with medical care and these characteristics are likely to affect patient satisfaction with treatment.

\section{REGULATORY ISSUES FOR TREATMENT SATISFACTION CLAIMS}

Measures of treatment satisfaction are important secondary end points for evaluating the outcomes of new treatments for GORD. Given the association between treatment satisfaction and adherence and willingness to continue taking a treatment, this outcome measure may provide insight into patient behaviour related to achieving the full effects of the treatment. To our knowledge, there are no examples of the use of treatment satisfaction measures in evaluating medical treatments and in obtaining regulatory claims for GORD treatments. Given the interest in PROs and the focus of the pharmaceutical industry in demonstrating product value, in terms of patient outcomes, treatment satisfaction end points may receive more attention.

It is likely that the USA Food and Drug Administration will review treatment satisfaction claims based on the same criteria used for other PRO claims, such as HRQoL. ${ }^{39}{ }^{40}$ The European Authorities do not have a policy for treatment satisfaction outcomes and will probably evaluate these claims based on data submitted by industry sponsors. ${ }^{41}$ Any approved claim will require demonstrated safety and clinical efficacy before any consideration of PROs, such as treatment satisfaction. Treatment satisfaction claims will need to be based on scientifically adequate and well controlled study designs, psychometrically sound instruments, appropriate and a priori declared statistical analysis methods, and complete and fair reporting of findings. It will also be important to clearly delineate guidelines for interpreting minimally important differences or effects for treatment satisfaction instruments.

\section{SUMMARY}

In summary, the current state of the art in measuring treatment satisfaction is incomplete and the existing measurement is insufficient. Research suggests that patients report high rates of satisfaction with surgical treatments (85$92 \%$ ) and medical treatments for GORD (70-94\%). The existing published studies use single item or global measures, and multi-item multidomain treatment satisfaction measures are needed to assess outcomes of GORD treatments. Methodological problems in assessing treatment satisfaction, related to acquiescent response bias and use of attitude response scales, skew individual responses to satisfaction questions, inflate reliability estimates, and may bias treatment comparisons for older, low education, and low income subgroups. Willingness to pay studies may be helpful in understanding important treatment characteristics for GORD

Table 3 Correlations between treatment satisfaction questionnaire, symptoms, and health related quality of life

\begin{tabular}{lcccc}
\hline & & \multicolumn{2}{l}{ SF-36 } \\
\cline { 4 - 4 } TSQ scale & GSRS reflux & QOLRAD total & PCS & MCS \\
\hline Symptom & $-0.60^{* *}$ & $0.70^{* *}$ & $0.41^{* *}$ & $0.35^{* *}$ \\
Satisfaction & $-0.57^{* *}$ & $0.65^{* *}$ & $0.33^{* *}$ & $0.30^{* *}$ \\
PRN & 0.11 & -0.09 & 0.04 & -0.08 \\
Expectations & $-0.20^{*}$ & 0.14 & $0.27^{*}$ & 0.02 \\
Cost & $-0.24^{* *}$ & $0.33^{* *}$ & $0.27^{*}$ & $0.20^{*}$ \\
Physician & $-0.28^{* *}$ & $0.36^{* *}$ & 0.11 & $0.25^{*}$ \\
Bother & -0.04 & $0.20^{*}$ & 0.10 & 0.10 \\
\hline
\end{tabular}

$T S Q$, treatment satisfaction questionnaire; GSRS, gastrointestinal symptoms rating scale; QOLRAD, quality of life in reflux and dyspepsia; PCS, physical component summary; MCS, mental component summary. ${ }^{*} \mathrm{p}<0.01 ;{ }^{* *} \mathrm{p}<0.0001$.

Source: Coyne and Revicki, unpublished data, 2002. 
from the patient's perspective, ${ }^{41}$ although Ross and colleagues $^{9}$ found that these methods may not be useful for measuring satisfaction with medical care.

Future instrument development for clinical trials requires more attention to conceptual issues, patient based qualitative research, and evaluation of psychometric qualities. More data are needed on how to interpret scores on treatment satisfaction measures, and on identifying minimally important differences or changes in these scores. Treatment satisfaction may be important for differentiating among GORD treatments and for monitoring patient outcomes in clinical practice, but the current status of measurement needs improvement.

\section{REFERENCES}

1 Rentz A, Battista C, Jones R, et al. Symptom and health-related quality of life measures for gastrointestinal disease studies: review and synthesis. Pharmacoeconomics 2001;19:349-63.

2 Weaver M, Patrick DL, Markson LE, et al. Issues in the measurement of satisfaction with treatment. Am J Manag Care 1997;3:579-94.

3 Ware JE, Snyder MK, Wright WR, et al. Defining and measuring patient satisfaction with medical care. Eval Program Plann 1984;6:247-63.

4 Pascoe GC. Patient satisfaction in primary health care: a literature review and analysis. Eval Program Plann 1983:6:185-210.

5 Van Campen C, Sixma H, Friele RD, et al. Quality of care and patient satisfaction: a review of measuring instruments. Med Care Res Rev 1995;52:109-33.

6 Kravitz RL. Patients' expectations for medical care: an expanded formulation based on review of the literature. Med Care Res Rev 1996:53:3-27.

7 Nunnally JC, Bernstein IH. Psychometric theory, 3rd edn. New York: McGrawHill, 1994.

8 Ware JE, Hays RD. Methods for measuring patient satisfaction with specific medical encounters. Med Care 1988;26:393-402.

9 Ross CK, Steward CA, Sinacore JM. A comparative study of seven measures of patient satisfaction. Med Care 1995;33:392-406.

10 Kaver WKH, Peters JH, DeMeester TR, et al. A tailored approach to antireflux surgery. J Thorac Cardiovasc Surg 1995;110:141-7.

11 Coster DD, Bower WH, Wilson VT, et al. Laparoscopic nissen fundoplication-a curative, safe, and cost-effective procedure for complicated gastroesophageal reflux disease. Surg Laparosc Endosc 1995;2:111-17.

12 Rattner DW, Brooks DC. Patient satisfaction following laparoscopic and open antireflux surgery. Arch Surg 1995;130:289-94.

13 Watson DI, Foreman D, Devitt PG, et al. Preoperative endoscopic grading of esophagitis versus outcome after laparoscopic nissen fundoplication. Am J Gastroenterol 1997;92:222-5.

14 Spivak H, Farrell TM, Trus TL, et al. Laparoscopic fundoplication for dysphagia and peptic esophageal stricture. J Gastrointest Surg 1998;2:555-60.

15 Klingler PJ, Hinder RA, Cina RA, et al. Laparoscopic antireflux surgery for the treatment of esophageal strictures refractory to medical therapy. Am J Gastroenterol 1999;94:632-6.

16 Hatlebakk JG, Johnsson F, Vilien $M$, et al. The effect of cisapride in maintaining symptomatic remission in patients with gastro-oesophageal reflux disease. Scand J Gastroenterol 1997;32:1100-6.

17 Bate CM, Green JRB, Axon ATR, et al. Omeprazole is more effective than cimetidine for relief of all grades of gastro-oesophageal reflux diseaseassociated heartburn, irrespective of the presence or absence of endoscopic oesophagitis. Aliment Pharmacol Ther 1997;11:755-63.

18 Johannessen T, Kristensen P. On-demand therapy in gastroesophageal reflux disease: a comparison of the early effects of single doses of fast-dissolving famotidine wafers and ranitidine tablets. Clin Ther 1997;19:73-81.
19 Elm M, Hellke P, Andren K, et al. Time to relief of episodic symptoms of gastrooesophageal reflux disease. A crossover comparison of single doses of the effervescent and standard formulations of ranitidine. Scand J Gastroenterol 1998;33:900-4.

20 Engzelius JM, Solhaug JH, Knapstad $\sqcup$, et al. Ranitidine effervescent and famotidine wafer in the relief of episodic symptoms of gastro-oesophageal reflux disease. Scand J Gastroenterol 1997;32:513-18.

21 Wilhelmsen I, Hatlebakk JG, Olafsson S, et al. On demand therapy of reflux oesophagitis - a prospective study of symptoms, patient satisfaction and quality of life. Aliment Pharmacol Ther 1999;13:1035-40.

22 Nelson WW, Vermeulen LC, Geurkink EA, et al. Clinical and humanistic outcomes in patients with gastroesophageal reflux disease converted from omeprazole to lansoprazole. Arch Intern Med 2000;160:2491-6.

23 Mathias SD, Colwell HH, Miller DP, et al. Health-related quality-of-life and quality-days incrementally gained in symptomatic non-erosive GORD patients treated with lansoprazole or ranitidine. Dig Dis Sci 2001;46:2416-23.

24 Robinson M, Fitzgerald S, Hegedus R, et al. Onset of symptom relief with rabeprazole: a community-based, open-label assessment of patients with erosive oesophagitis. Aliment Pharmacol Ther 2002;16:445-54.

25 Crawley JA, Schmitt CM. How satisfied are chronic heartburn suffers with their prescription medications? Results of the patient unmet needs survey. J Clin Outcomes Manag 2000;7:29-34.

26 Colwell HH, Mathias SD, Pasta DJ, et al. Development of a health-related quality-of-life questionnaire for individuals with gastroesophageal reflux disease. Dig Dis Sci 1999:44:1376-83.

27 Velenovich V, Vallance SR, Gusz JR, et al. Quality of life scale for gastroesophageal reflux disease. J Am Coll Surg 1996;183:217-24.

28 Rabeneck L, Cook K, Wristers K, et al. SODA (severity of dyspepsia assessment): a new effective outcome measure for dyspepsia-related health. J Clin Epidemiol 2001;54:755-65.

29 Carr-Hill RA. The measurement of patient satisfaction. J Public Health Med 1992; 14:236-49

30 Hays RD, Ware JE. My medical care is better than yours: social desirability and patient satisfaction ratings. Med Care 1986;24:519-25.

31 Ware JE. Effects of acquiescent response set on patient satisfaction ratings Med Care 1978;16:327-36.

32 Tourangeau R, Rasinski KA. Cognitive processes underlying context effects in attitude measurement. Psychol Bull 1988;103:299-314.

33 Hall JA, Dornan MC. Patient sociodemographic characteristics as predictors of satisfaction with medical care: a meta-analysis. Soc Sci Med 1990;30:811-18.

34 Marshall GN, Hays RD, Mazel R. Health status and satisfaction with health care: results from the medical outcomes study. J Consult Clin Psychol 1996:64:380-90.

35 Kurata JH, Nogawa AN, Chen YK, et al. Dyspepsia in primary care: perceived causes, reasons for improvement, and satisfaction with care. J Fam Pract 1997; 44:281-8.

36 Williams S, Weinman J, Dale J. Doctor-patient communication and patient satisfaction: a review. Fam Pract 1998;15:480-92.

37 Williams S, Weinman J, Dale J, et al. Patient expectations: what do primary care patients want from the GP and how far does meeting expectations affect patient satisfaction? Fam Pract 1995;12:193-201.

38 Staniszewska S, Ahmed L. The concept of expectations and satisfaction: do they capture the way patients evaluate their care? J Adv Nurs 1999;29:364-72.

39 Leidy NK, Revicki DA, Geneste B. Recommendations for evaluating the validity of quality of life claims for labeling and promotion. Value Health 1999;2:113-17.

40 Revicki DA, Osoba D, Fairclough D, et al. Recommendations on health-related quality of life research to support labeling and promotional claims in the United States. Qual Life Res 2000;9:887-900.

41 Chassany O, Sagnier P, Marquis P, et al. Patient-reported outcomes: the example of health-related quality of life-a European guidance document for the improved integration of health-related quality of life assessment in the drug regulatory process. Drug Inf J 2002;36:209-18. 